\title{
THERMAL ENERGY CONSUMPTION IN THE HEAT- TECHNOLOGY PRODUCTION OF SOLID COMPOSITE FUEL FROM LOW-GRADE RAW MATERIALS
}

\author{
Roman Tabakaev ${ }^{1,}$, Alexander Astafev ${ }^{1}$, Alexander Kazakov ${ }^{1}$ and Alexander Zavorin ${ }^{1}$ \\ ${ }^{1}$ National Research Tomsk Polytechnic University, 634050 Tomsk, Russia
}

\begin{abstract}
An evaluation is made of the thermal energy consumed in the heat-technology production of solid composite fuel from low-grade organic raw materials. It is shown that the heat of decomposition of the organic mass and the combustion of the by-products of heattechnology may be sufficient to cover all the energy needs for processing peat, brown coal and wood chips. Producing solid composite fuel from sapropel requires external resources to compensate for part of the heat consumed. Calculations show that it is possible for the thermal processing of raw materials to proceed autothermally due to the heat of decomposition when the moisture content at the reactor inlet is limited: for peat it should be no more than $35 \%, 54 \%$ for brown coal, and $37 \%$ for wood chips. The low heat of decomposition of the sapropel organic mass means that its thermal processing cannot proceed autothermally.
\end{abstract}

\section{Introduction}

The gradual depletion of high-quality energy resources such as natural gas and coal, as well as the need to use them in the chemical industry and metallurgy, has made it necessary to take a new look at the future of the energy industry. Currently more than 70 countries have adopted national programs aimed at increasing the share of renewable resources in the fuel and energy balance [1].

As a model for the evolution of the energy industry, the Russian Federation has developed a program called "Russia's Strategy for Energy Development up to 2030", which was approved by the government and envisages a gradual decrease in natural gas and replacing that energy with renewable resources, low-grade organic raw materials (LR), such as peat, biomass, low-grade brown coal, sapropel, etc. It has also been noted that it would be advantageous to use LR in areas with a decentralized energy supply that receive energy from stand-alone power plants running on fuel that has been brought in. Most of this fuel is supplied by commercial organizations of the secondary market after resale, which, along with the annual increase in transportation fees, raises its costs.

LR in the natural state is rarely used as a fuel due to the high operating costs associated with traditional methods of burning it. These expenses are due to the high moisture and ash content of LR, which give it a lower calorific value based on the operating conditions and correspondingly high costs, and the need to pre-dry it. Moreover, the high moisture content causes the raw materials to be sticky and congeal when they are transported in the winter [2], requiring additional time and money to heat

\section{a Corresponding author: TabakaevRB@tpu.ru}

This is an Open Access article distributed under the terms of the Creative Commons Attribution License 4.0, which permits unrestricted use, distribution, and reproduction in any medium, provided the original work is properly cited. 
railcars. LR has high sifting values when used in bed combustion systems because of its low mechanical strength and high friability.

For decades researchers have been looking at ways to use LR effectively in the energy industry, and as a result, it has been processed into fuel briquettes, has been gasified, has undergone catalytic combustion, biofuels have been made from it, etc. One of the promising and popular solutions has been the heat-technology processing of LR into energy products which are then used to manufacture solid composite fuel (SCF) - fuel briquettes and pellets. However, one of the main criticisms of this process [3] is that thermotechnical processing wastes an excessive amount of energy resources and raw materials and produces too many environmentally harmful emissions.

The purpose of this research was to determine the thermal energy consumed when producing SCF from low-grade raw materials using the heat-technology developed by the authors.

\section{The main aspects of the heat-technology}

The heat-technology [4-6] consists of the preliminary thermal processing of LR into energetically valuable products (carbon residue and pyrolysis condensate) and the subsequent formation of SCF (Fig. 1). We chose pyrolysis at a temperature not exceeding $450{ }^{\circ} \mathrm{C}$ as the thermal processing method for the LR. This process temperature allowed us to use available, regular-grade carbon steel to make the technical equipment, thereby minimizing the cost of materials and assembly.

The gas produced as a by-product of thermal processing was combusted to cover the thermal losses of the heat-technology.

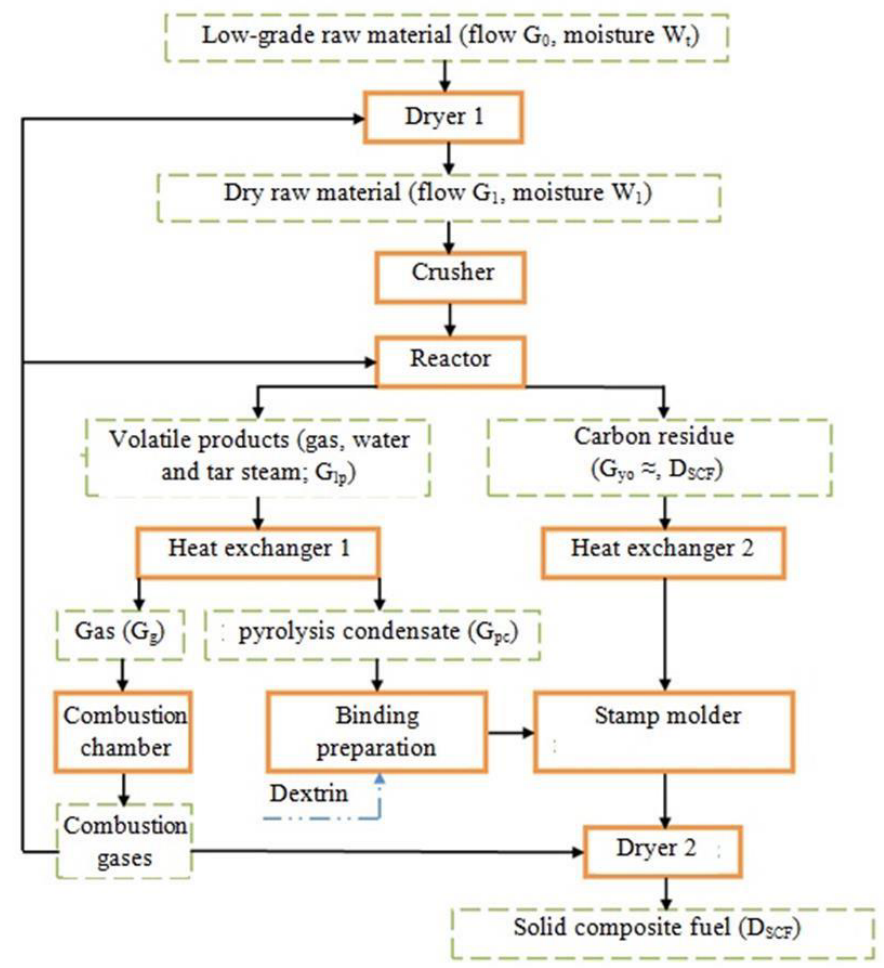

Figure 1. Diagram of processing solid composite fuel: $\mathrm{G}_{0}$ is the $\mathrm{LR}$ flow, $\mathrm{kg} / \mathrm{s} ; \mathrm{W}_{\mathrm{t}}$ is the moisture content of $\mathrm{LR}$, $\% ; \mathrm{G}_{1}$ is the LR flow after drying in dryer $1, \mathrm{~kg} / \mathrm{s} ; \mathrm{W}_{1}$ is the moisture content of LR after drying, $\% ; \mathrm{G}_{\mathrm{lp}}$ is the flow of volatile products released during pyrolysis, $\mathrm{kg} / \mathrm{s} ; \mathrm{G}_{\mathrm{yo}}$ is the flow of carbon residue produced in the pyrolysis, $\mathrm{kg} / \mathrm{s} ; \mathrm{D}_{\mathrm{SCF}}$ is the SCF production rate, $\mathrm{kg} / \mathrm{s} ; \mathrm{G}_{\mathrm{g}}$ is the gas flow rate, $\mathrm{kg} / \mathrm{s} ; \mathrm{G}_{\mathrm{pc}}$ is the flow of pyrolysis condensate, $\mathrm{kg} / \mathrm{s}$. 
The SCF is formed with a binder obtained by dissolving dextrin in the pyrolysis condensate in a ratio of 1:10 [4] and carbon residue with particle sizes less than $2 \mathrm{~mm}$. For this, carbon residue is mixed with a binder in a ratio of 2:3, the SCF is formed and the brick is dried at from 20 to $40{ }^{\circ} \mathrm{C}$ for making briquettes and at from 20 to $80^{\circ} \mathrm{C}$ for pellets [5].

\section{Experimental setup and study technique}

The thermotechnical characteristics of the initial LR obtained by processing products and the SCF were determined by standard methods (GOST [Russian State Standard] R 52917-2008, GOST R 52911-2008, GOST 11022-95, GOST 6382-2001, GOST 147-95).

Preliminary thermal processing of LR was conducted with laboratory equipment (Fig. 2). The LR was loaded into reactor 1 , after which the reactor was hermetically sealed and placed in heating element 2, carrying the heat to the reactor over its entire cylindrical surface. The heating level was set with autotransformer 3, focusing on the readings of ammeter 4 and voltmeter 5. A system of thermocouples 6 on top of the fuel bed and in the fuel bed (in the centre and in the periphery) was used to measure the temperature of the process, and a TM902C thermometric sensor connected to them.

a)

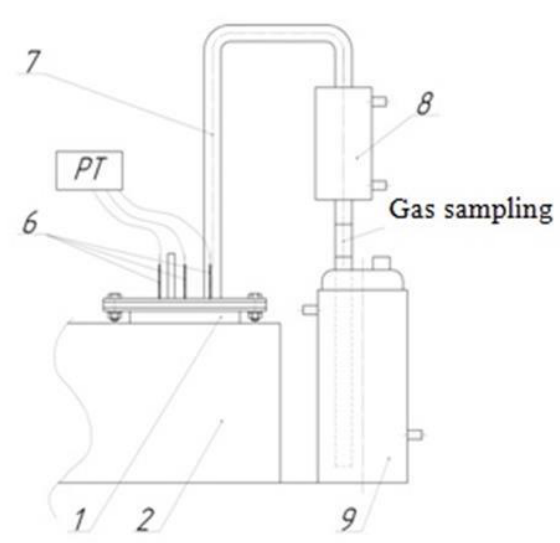

b)

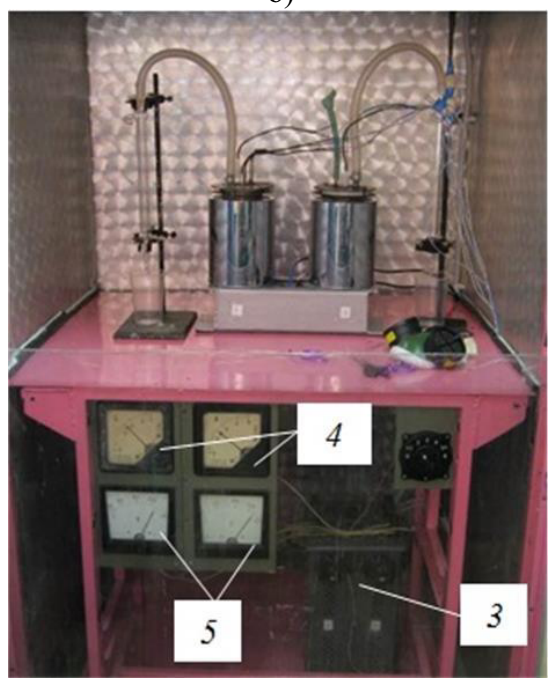

Figure 2. Laboratory equipment for the thermal processing of LR: a) principle diagram; b) a view of the assembly; 1 - reactor, 2 - heating element, 3 - autotransformer, 4 - ammeter, 5 - voltmeter, 6 - thermocouple system, 7 - heat-resistant hose, 8 - refrigerator, 9 - tank.

The refrigerator 8 and refrigerated tank 9 were added to capture the volatile products (fumes of pyrogenetic water and tar, gas) generated during thermal processing that left reactor 1 via heatresistant hose 7. Gas samples were taken for analysis at the junction of refrigerator 8 and tank 9 . When the process ended, the carbon residue was removed from air-cooled reactor, the condensate from tank 9 was passed through filter paper to separate pyrogenetic moisture and tar. The resulting products were weighed, and the mass of the gas was determined as the difference between the mass of the initial raw material and the mass of the other products (semi-coke, pyrogenetic moisture, and tar).

The heat of decomposition of the organic mass was determined by taking the heat emitted by the dry raw material and subtracting from it the total heat emitted by all the resulting products, taken as $1 \mathrm{~kg}$.

The SCF bricks were made with stamping forms (Fig. 3). The strength properties of the SCF were determined according to standard methods (GOST 21289-75 and GOST 18132-72). 
a)

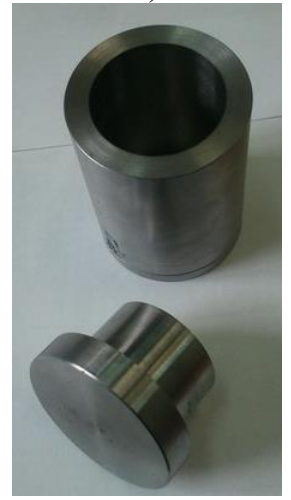

b)

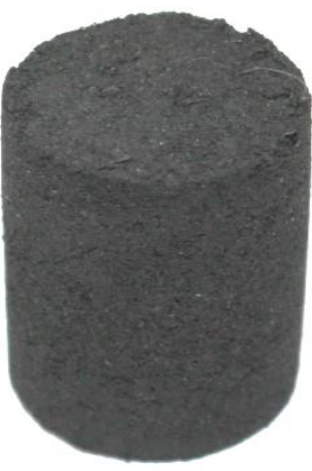

Figure 3. Stamping form (a) and the raw SCF produced (b).

\section{The results of studying the SCF obtained}

The production of SCF was investigated using several types of LR from the Tomsk region: peat from Kandinsky deposits, brown coal from Talovsky deposits, wood chips from different tree species, and lake sapropel from Karasevsky deposit.

As a result of the pyrolysis of these $\mathrm{LR}$ (at $450^{\circ} \mathrm{C}$, raw material heating rate of $10{ }^{\circ} \mathrm{C} /$ minute), the material balance is given (Fig. 4).

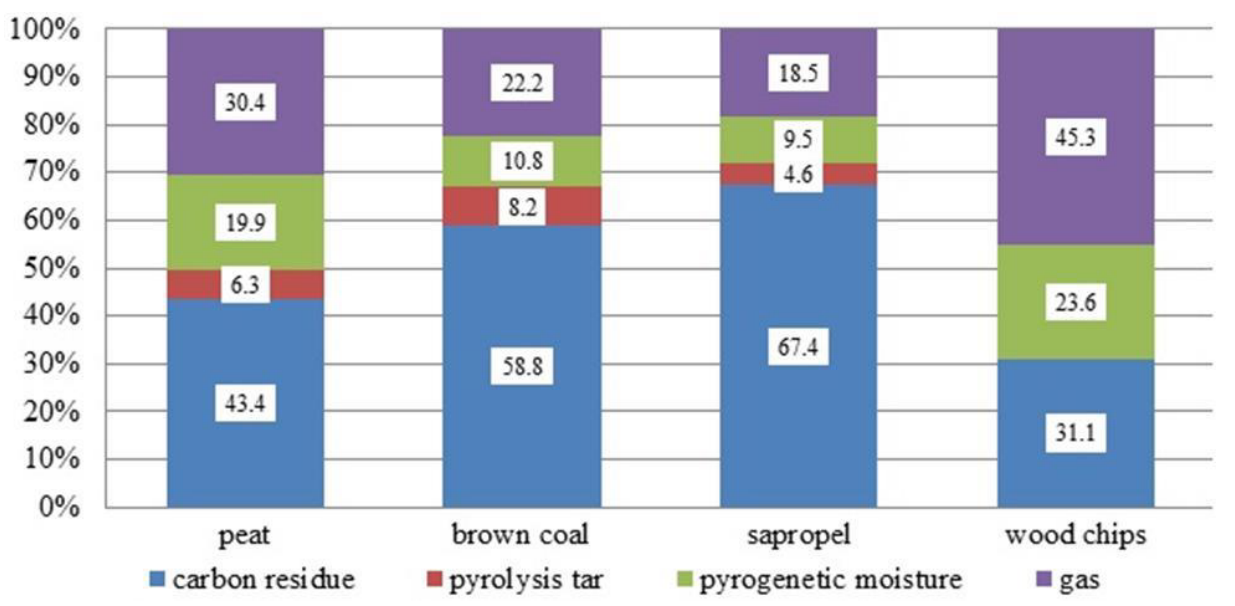

Figure 4. Material balance of low-temperature pyrolysis (relative to the dry weight of the initial raw material).

Low-temperature pyrolysis of dried LR is accompanied by a positive heat emission of 0.33-3.69 $\mathrm{MJ} / \mathrm{kg}$ [5], which is characteristic for fuels in the early stages of metamorphism. When the gas byproduct of heat-technology is burned, from 2.70 to $6.67 \mathrm{MJ}$ of thermal energy can be obtained per kilogram of dry processed raw materials. Thus, in the course of thermal processing, 26-38\% of the possible heat emitted from the LR can be directed to cover the thermal needs of producing SCF.

The characteristics of the LR and the SCF obtained from it with this heat-technology are shown in Table 1.

Due to the nature of processing, the SCF has a higher ash content and less volatile substances than the initial LR, but its lowest calorific value is 2.1-6.8 times higher [6]. Moreover, the fuel has mechanical strength, according to GOST R 54248-2010, sufficient for use in the housing and utilities 
sector: $100 \%$ resistance to fracture when dropped, and a compression resistance of over $0.3 \mathrm{MPa}$ (test method GOST 21289-75).

Table 1. Thermotechnical characteristics of the initial raw material and the SCF obtained from it.

\begin{tabular}{|c|c|c|c|c|}
\hline Thermotechnical properties & Peat & Brown coal & Sapropel & Wood chips \\
\hline & & \multicolumn{3}{|c|}{ Initial raw material/solid composite fuel } \\
\hline Moisture content $W_{t}^{r}, \%$ & $72.8 / 0$ & $51.0 / 0$ & $67.0 / 0$ & $45 / 0$ \\
\hline Ash per dry mass $A^{d}, \%$ & $9.1 / 19.1$ & $25.9 / 32.1$ & $38.4 / 47.1$ & $0.6 / 2.9$ \\
\hline Yield of volatile substances per fuel weight $V^{\text {daf }}, \%$ & $71.6 / 19.4$ & $63.2 / 10.6$ & $84.8 / 16.5$ & $91.8 / 13.1$ \\
\hline Lowest calorific value $Q_{i}^{r}, \mathrm{MJ} / \mathrm{kg}$ & $3.1 / 21.1$ & $8.6 / 18.0$ & $2.1 / 11.6$ & $9.3 / 29.4$ \\
\hline
\end{tabular}

\section{Heat consumed to produce SCF}

In the production of SCF, thermal energy is needed for drying the initial raw material, processing it, and drying the brick. The necessary heat can be estimated as follows.

Heat to dry the LR:

$$
Q_{d l}=\left(G_{0^{-}}-G_{1}\right) \cdot r, k W,
$$

where $r$ is the heat of vaporization, $\mathrm{kJ} / \mathrm{kg}$.

Heat to dry the SCF brick (at a 2:3 ratio of carbon residue to binder):

$$
Q_{d 2}=1.5 \cdot G_{y o} \cdot r, k W,
$$

Heat for the thermal processing of LR can be divided into several components: evaporation of residual water $\left(Q_{t p l}\right)$, heating the raw material to the temperature at which thermal decomposition starts $\left(Q_{t p 2}\right)$, pyrolysis $\left(Q_{t p 3}\right)$, loss with the physical heat of volatile products $\left(Q_{t p 4}\right)$. The calculation must take into account the heat loss of the decomposition of organic mass of the LR $\left(Q_{d e c}\right)$ and the heat loss into the environment $\left(Q_{5}\right)$. Thus, the formula for determining the heat required for thermal processing is:

$$
Q_{T P}=Q_{t p 1}+Q_{t p 2}+Q_{t p 3}+Q_{t p 4}+Q_{5}-Q_{d e c},
$$

where $Q_{t p l}=G_{I} \cdot W_{I} \cdot r, \mathrm{~kW}$;

$Q_{t p 2}=C_{p}^{L R} \cdot G_{I} \cdot\left(1-W_{1}\right) \cdot\left(t_{t p}-20\right), \mathrm{kW}$;

$C p^{\mathrm{LR}}$ is the heat capacity of the $\mathrm{LR}, \mathrm{kJ} /\left(\mathrm{kg} \cdot{ }^{\circ} \mathrm{C}\right)$;

$t_{t p}$ is the temperature at which thermal decomposition of the LR begins, ${ }^{\circ} \mathrm{C}$;

$Q_{t p 3}=C_{p}^{c r} \cdot 0,5 \cdot\left(G_{1} \cdot\left(1-W_{l}\right)+G_{y o}\right) \cdot\left(450-t_{t p}\right), \mathrm{kW}$

$Q_{t p 4}=C_{p}^{p c} \cdot\left(G_{I} \cdot\left(1-W_{1}\right)-G_{y o}\right) \cdot\left(450-t_{t p}\right), \mathrm{kW}$;

$C_{p}^{c r}$ is the heat capacity of carbon residue, $\mathrm{kJ} /\left(\mathrm{kg} \cdot{ }^{\circ} \mathrm{C}\right)$;

$C_{p}^{p c}$ is the heat capacity of volatile products released during pyrolysis, $\mathrm{kJ} /\left(\mathrm{kg} \cdot{ }^{\circ} \mathrm{C}\right)$;

$Q_{5}$ is the loss into the environment, $\mathrm{kW}$;

$Q_{d e c}=G_{I} \cdot\left(1-W_{l}\right) \cdot Q_{d e c}{ }^{L R}, \mathrm{~kW}$;

$Q_{d e c}{ }^{L R}$ is the heat of decomposition of the organic mass of LR (determined by [5]).

Assuming that the heat of decomposition of the organic mass of LR $\left(Q_{\text {dec }}\right)$ will be sufficient to cover the heating needs $\left(Q_{t p 1}, Q_{t p 2}, Q_{t p 3}, Q_{t p 4}\right.$ and $\left.Q_{5}\right)$, then (3) will be:

$$
Q_{d e c}=Q_{t p 1}+Q_{t p 2}+Q_{t p 3}+Q_{t p 4}+Q_{5}
$$

In this case finding the solution comes down to determining the moisture content of the LR after dryer $1\left(W_{l}\right)$. When the LR enters the reactor with moisture content $W_{l}$ less than calculated, the pyrolysis process will proceed autothermally. 
A source of heat in addition to the heat of decomposition of organic mass for this thermotechnology is heat $\left(Q_{g}\right)$ from the combustion of gas. The results of the thermal calculation of small-tonnage production of SCF (45 tons/day) are shown in Table. 3. Here it is assumed that, due to long-term outdoor storage after extraction, the initial LR will enter drier 1 with a moisture content of $45 \%$ [7].

The calculation shows that when processing peat, brown coal, and wood chips into SCF, the heat generated by the decomposition of the organic mass and the combustion of gas is sufficient to cover the thermal needs of heat-technology. Moreover, low-temperature pyrolysis can proceed autothermally when LR is dried in dryer 1 to the following moisture contents $\left(W_{1}\right): 35 \%$ for peat, $37 \%$ for wood-chips, and 54\% for brown coal (there is no need for drier 1).

When producing SCF from sapropel, external resources are needed to cover about $1700 \mathrm{~kW}$ of heat consumed.

Table 2. Thermal losses and heat emission in the production of SCF (45 tons/day).

\begin{tabular}{|c|c|c|c|c|c|c|c|c|c|c|c|}
\hline \multirow{3}{*}{$\begin{array}{l}\text { Low-grade } \\
\text { raw materials }\end{array}$} & \multirow{2}{*}{$W_{1}$} & \multirow{2}{*}{$\mathbf{Q}_{\mathrm{d} 1}$} & \multirow{2}{*}{$\mathbf{Q}_{\mathrm{d} 2}$} & \multicolumn{5}{|c|}{$\mathbf{Q}_{\mathrm{d} 3}$} & \multirow{2}{*}{$\mathbf{Q}_{\text {dec }}$} & \multirow{2}{*}{$\mathbf{Q}_{\mathrm{g}}$} & \multirow{2}{*}{$\begin{array}{l}\text { Total heat consumed } \\
\text { and heat emitted }\end{array}$} \\
\hline & & & & $\mathrm{Q}_{\mathrm{tp} 1}$ & $\mathrm{Q}_{\mathrm{tp} 2}$ & $\mathrm{Q}_{\mathrm{tp} 3}$ & $\mathrm{Q}_{\mathrm{tp} 4}$ & $\mathrm{Q}_{5}$ & & & \\
\hline & $\%$ & \multicolumn{10}{|c|}{$k W$} \\
\hline peat & 35 & -301 & \multirow{4}{*}{-1760} & -1444 & -149 & -207 & -1080 & -29 & 2604 & 5497 & 3131 \\
\hline brown coal & 54 & 0 & & -2310 & -322 & -229 & -385 & -32 & 3247 & 2609 & 818 \\
\hline sapropel & - & $\begin{array}{l}-1421 \\
\end{array}$ & & 0 & -257 & -192 & -332 & -8 & 254 & 2043 & -1673 \\
\hline wood chips & 37 & -341 & & -2188 & -496 & -396 & -913 & -40 & 3991 & 11195 & 10812 \\
\hline
\end{tabular}

\section{Conclusions}

1) Using the heat of decomposition of the organic mass of fuel and the heat of combustion of the byproducts of thermal processing, it is possible to completely cover the thermal needs of the heattechnology production of solid composite fuel from peat, brown coal, and wood chips. Producing fuel from sapropel requires external resources to compensate for part of the heat consumed.

2) Low-temperature pyrolysis of these low-grade raw materials can proceed autothermally due to the heat of decomposition of the organic mass, provided the water content of the raw materials at the reactor inlet does not exceed the following: $35 \%$ for peat, $54 \%$ for brown coal, and $37 \%$ for wood chips. For this, the initial raw material must be preliminarily dried. The low heat of decomposition of the organic mass of lake sapropel means that its thermal processing cannot proceed autothermally.

\section{Acknowledgments}

The reported study was partially supported by the Ministry of education and science of The Russian Federation, state order No. 2069 and No. 13.948.2014/K.

\section{References}

1. O. S. Popel, B. F. Reutov, A. P. Antropov, Thermal engineering, 57, 909 (2010)

2. A. D. Uchitel, M. V. Kormer, V. P. Lyalyuk, I. A. Lyakhova, E. O. Shmeltser, Y. I. Vititnev, Coke and Chemistry, 56, 167 (2013)

3. A. V. Klimenko, V. M. Zorin, Teplojenergetika i teplotehnika: Obshhie voprosy [Heat-power and heat-technology: general issues] (MEI, Moscow, 1999) [in Russian] 
4. R. B. Tabakaev, P. S. Gergelizhiu, A. V. Kazakov, A. S. Zavorin, IOP Conference Series: Materials Science and Engineering, 66, 012052 (2014)

5. R. B. Tabakaev, A. V. Kazakov, A. S. Zavorin, Solid Fuel Chemistry, 49, 267 (2015)

6. R. B. Tabakaev, A. V. Astafev, A. V. Kazakov, A. S. Zavorin, M. Polsongkram, IOP Conference Series: Materials Science and Engineering, 93, 012017 (2015)

7. V. I. Kolotushkin, Spravochnaja knizhka torfjanika [Reference book of the peat bog] (Nedra, Moscow, 1973) [in Russian] 